\title{
$\alpha$-Catenin expression is decreased in human gastric cancers and in the gastric mucosa of first degree relatives
}

J Yu, M P A Ebert, S Miehlke, H Rost, U Lendeckel, A Leodolter, M Stolte, E Bayerdörffer, P Malfertheiner

\begin{abstract}
Background and aims-The role of altered cell adhesion is critical for the development of epithelial cancers. E-cadherin plays an important role in the maintenance of cell-cell adhesion and its function is thought to be regulated by its associated cytoplasmic proteins, such as $\alpha$-catenin and $\beta$-catenin. To determine the role of $\alpha$-catenin expression in gastric carcinogenesis, we studied its expression in human gastric cancer and in the gastric mucosa of first degree relatives with no clinical disease.
\end{abstract}

Methods-a-Catenin expression was assessed by immunohistochemical analysis and reverse transcriptase-polymerase chain reaction (RT-PCR) using gastric tissue specimens from patients with gastric cancer and from the gastric mucosa of first degree relatives of gastric cancer patients and healthy controls.

Results-mRNA levels of $\alpha$-catenin were reduced or absent in 13 of 19 gastric cancer tissues, which differed significantly from levels found in the tumour free gastric mucosa of cancer patients $(p<0.05)$. Of the cancer samples with altered $\alpha$-catenin mRNA levels, $\alpha$-catenin expression was negative in seven and decreased in six cases. Interestingly, decreased $\alpha$-catenin mRNA expression also occurred in the mucosa of the corpus (11/ 18) and antrum (4/18) of first degree relatives. In the corpus biopsies $\alpha$-catenin expression was more often decreased or lost compared with the antrum biopsies in first degree relatives and healthy controls $(p<0.05)$. Immunohistochemical analysis revealed membranous expression of $\alpha$-catenin in gastric cancer cells and the non-malignant gastric epithelium. However, some cancers also exhibited loss of membranous staining. Generally, loss or downregulation of $\alpha$-catenin mRNA in the gastric mucosa was associated with Helicobacter pylori infection $(\mathrm{p}<0.05)$.

Conclusion-Our findings suggest that loss or downregulation of $\alpha$-catenin expression may be an early event in gastric carcinogenesis and may be associated with $H$ pylori infection.

(Gut 2000;46:639-644)

Keywords: risk; stomach; gene; cadherins; gastric cancer; $\alpha$-catenin
Cadherins are calcium dependent transmembranous proteins which appear to mediate cellcell adhesion through homophilic interactions. ${ }^{12}$ E-cadherin belongs to the cadherin superfamily and is involved in maintenance of the epithelial phenotype. ${ }^{3-5}$ Its function depends on the ability of its cytoplasmic sequence to link to the submembranous cytoskeletal matrix through interaction with proteins called catenins. ${ }^{6}{ }^{7}$ Catenins have been classified into $\alpha, \beta$, and $\gamma$ based on electrophoretic mobility. ${ }^{8}$ They are necessary for E-cadherin functions, of which $\alpha$-catenin is believed to be important in linking E-cadherin to the actin cytoskeleton and co-localises with E-cadherin at the adherens junction. ${ }^{9}$ The interaction of $\beta$-catenin bound to the cytoplasmic domain of E-cadherin with the actin cytoskeleton is mediated by $\alpha$-catenin. Thus loss of $\alpha$-catenin expression may lead to impaired formation of adherens junctions, despite normal E-cadherin and $\beta$-catenin expression..$^{10}$

Formation of metastases is a complex process which includes reduction of cell adhesion, invasion of neighbouring tissues, and release of cancer cells into the blood or lymphatic stream. However, loss of cell adhesion may not only contribute to formation of metastases, it may also be responsible for loss of contact inhibition of epithelial cells and thus may play a role in the early phase of malignant transformation of epithelial cells. ${ }^{11}$ Reduction or loss of E-cadherin expression has been described in gastric carcinoma, and mutations of E-cadherin occur in 50\% of diffuse-type gastric carcinomas. ${ }^{12}{ }^{13}$ Furthermore, reduced or total loss of $\alpha$-catenin expression was observed in $55-70 \%$ of gastric cancers. ${ }^{14} 15$ Therefore, alteration of expression of adhesion molecules seems to be a frequent event in gastric cancer. In tumours with normal E-cadherin expression, altered cell adhesion may also be explained by impaired function of catenins. ${ }^{16}$ Thus downregulation of $\alpha$-catenin expression could also interfere with cadherin mediated cell-cell adhesion, leading to impaired adhesion in cases of normal E-cadherin expression in human cancerous tissue.

In this study we examined $\alpha$-catenin expression in gastric cancer and in the gastric mucosa of first degree relatives of gastric cancer

Abbreviations used in this paper: $H$ pylori, Helicobacter pylori; IM, intestinal metaplasia; RT, reverse transcription; PCR, polymerase chain reaction; cDNA, complementary DNA.
Accepted for publication 25 November 1999 
patients by RT-PCR and immunohistochemical analysis to assess the role of $\alpha$-catenin in the process of gastric carcinogenesis and to evaluate its potential role as a marker for increased risk of developing cancer in patients with a family history of gastric cancer.

\section{Materials and methods SUBJECTS}

Tissue specimens were obtained by surgical resection or biopsy from 19 patients with gastric cancer from the tumour and from a tumour free location. In all cases at least two biopsies were taken from the tumour and a tumour free area, which was located at least 6 $\mathrm{cm}$ distant from the tumour. Histological evaluation of one of the two biopsies confirmed the presence of tumour cells in the biopsy taken from the tumour and the absence of cancer cells in the biopsy taken from the non-tumour location. The other biopsy was used for molecular analysis and snap frozen in liquid nitrogen. Ten males and nine females (mean age 62 years (range 35-73)) were enrolled in the study. Tissues were also obtained from 18 first degree relatives of gastric cancer patients from the corpus and antrum (four males; mean age 47 years (range 27-65)). Five patients with gastric cancer and their five first degree relatives were enrolled in the study. Other patients and first degree relatives were from different families. Tissues from eight subjects with dyspepsia and normal gastric mucosa at endoscopy, but with no family history of gastric cancer and a history of peptic ulcers were used as normal controls. All individuals gave informed consent to participate in this study. Immediately after removal all tissues for molecular analysis were placed in liquid nitrogen and stored at $-80^{\circ} \mathrm{C}$ until use. This study was approved by the ethics committees of the University of Magdeburg and the Technical University Hospital of Dresden, Germany.

HISTOLOGY

Formalin fixed tissues were processed as previously described and sections were stained with haematoxylin and eosin for histological evaluation and with Warthin-Starry stain for detection of Helicobacter pylori. ${ }^{17}$ Gastric cancers were classified histologically as intestinal-type $(n=9)$ or diffuse-type $(n=9)$ according to the Lauren system. The severity of gastritis and $H$ pylori colonisation of the non-tumorous gastric mucosa was histologically classified according to the updated Sydney system. ${ }^{17}$

mRNA ISOLATION

Tissue specimens were stored at $-80^{\circ} \mathrm{C}$ and homogenised with an ultrasound homogeniser (Ultra-Turrax T25, Janke and Kunkel GmbH, Germany) in the presence of RNAzolB (CINNA/MRC, Cincinnati, Ohio, USA) containing RNase inhibitors. Total RNA was extracted from frozen tissues by the acidguanidinum-thiocyanate method as previously described. ${ }^{18}$
RT-PCR ANALYSIS

Total RNA $(1 \mu \mathrm{g})$ was reverse transcribed using dNTPs (1 $\mathrm{mM})$, DTT $(5 \mathrm{mM})$, reverse transcription buffer ( $50 \mathrm{mM}$ Tris $\mathrm{HCl}, \mathrm{pH} 8.3$, $75 \mathrm{mM} \mathrm{KCl}, 3 \mathrm{mM} \mathrm{MgCl}_{2}$, and $1 \mathrm{mM}$ DTT), and $40 \mathrm{U}$ RNasin; 6 units of Superscript plus were added to a total volume of $20 \mu \mathrm{l}$. After incubation at $37^{\circ} \mathrm{C}$ for one hour the reaction was terminated by incubating the mixture at $95^{\circ} \mathrm{C}$ for 10 minutes. A pair of primers was designed to amplify the coding region of $\alpha$-catenin mRNA. A sense primer, Pr-1 (5'GAGCCAGTTTCTCAAGGAGGA-3'), corresponding to nucleotides 302-322, and an antisense primer, Pr-2 (5'-CGTCGATCTC CTTAGGACGTC-3'), corresponding to nucleotides 691-711, were used. ${ }^{19}$ The $30 \mu \mathrm{l}$ reaction mixture was incubated for 1.5 minutes at $95^{\circ} \mathrm{C}$. Samples were denatured at $96^{\circ} \mathrm{C}$ for 24 seconds, annealed at $58^{\circ} \mathrm{C}$ for 48 seconds, and extended at $72^{\circ} \mathrm{C}$ for one minute. After 35 cycles there was a final elongation for five minutes at $72^{\circ} \mathrm{C}$ and the samples were stored at $4^{\circ} \mathrm{C}$ until further use; $8 \mu \mathrm{l}$ of the PCR product was then electrophoresed on a $1.25 \%$ agarose gel together with size markers.

SEMIQUANTITATIVE ANALYSIS

Levels of $\alpha$-catenin mRNA were quantified using semiquantitative RT-PCR as previously described. ${ }^{2021} \beta$-Actin was used as an internal standard to confirm equal loading in each experiment and was amplified from the same cDNAs as previously described (fig 1). ${ }^{18}$ The level of $\alpha$-catenin mRNA was analysed densitometrically from the agarose gel and was standardised to the respective $\beta$-actin mRNA level. The $\alpha$-catenin $/ \beta$-actin ratio was calculated and analysed using the $t$ test. $^{22}$

\section{IMMUNOHISTOCHEMISTRY}

The presence of $\alpha$-catenin protein was assessed using formalin fixed, paraffin embedded gastric tissue sections obtained from gastric cancer patients $(n=8)$, gastric cancer relatives $(n=6)$, and healthy controls $(n=6)$. Sections of $4 \mu \mathrm{m}$ were deparaffinised in graded alcohol. ${ }^{18} \mathrm{~A}$ highly specific polyclonal antibody for $\alpha$-catenin (C-19) was obtained from Santa Cruz Biotechnology (Santa Cruz, California, USA). This antibody is directed against the carboxy terminus of $\alpha$-catenin and has previously been shown to be specific for $\alpha$-catenin

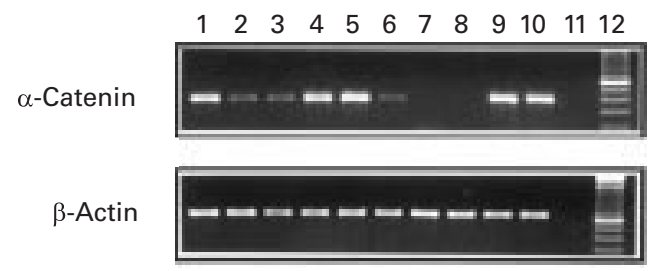

Figure 1 RT-PCR analysis of a-catenin $m R N A$ in gastric tissues. RT-PCR analysis was performed using specific primers for human a-catenin as described in materials and methods. Amplification of $\beta$-actin $m R N A$ was performed to ensure equal loading. Lanes 1-2: tumour free and tumour from patient No 1; lanes 3-4: corpus and antrum from relative No 6; lanes 6-7: tumour free and tumour from patient No 2; lanes 8-9: corpus and antrum from relative No 2; lanes 5 and 10: gastric mucosa from healthy subjects; lane 11: negative control; and lane 12: DNA ladder. 
using western blotting, immunoprecipitation, neutralisation experiments, and immunohistochemical analysis. ${ }^{15}$ For immunohistochemical analysis the antibody was used at a dilution of $1: 100$. For negative controls the primary antibody was omitted (not shown). All sections were subjected to microwave treatment for $2 \times 7$ minutes in citrate buffer. Endogenous peroxidase activity was inhibited by immersing the sections in $0.3 \% \mathrm{H}_{2} \mathrm{O}_{2}$. The sections were incubated with the antibody at $4^{\circ} \mathrm{C}$ overnight. Bound antibody was detected with a biotinylated antigoat IgG secondary antibody and streptavidin-peroxidase complex using diaminobenzidine tetrahydrochloride as the substrate. Sections were counterstained with Mayer's haematoxylin. ${ }^{18}$

\section{STATISTICAL ANALYSIS}

Fisher's exact test, $\chi^{2}$ and $t$ test were used to determine statistical differences, with $\mathrm{p}<0.05$ taken as the level of significance. ${ }^{22}$

\section{Results}

$\alpha$-CATENIN EXPRESSION IN GASTRIC CANCER

All gastric biopsies obtained from healthy control subjects exhibited $\alpha$-catenin mRNA, as determined by RT-PCR analysis. In contrast, in 13 of 19 tumour samples, $\alpha$-catenin mRNA levels were altered (table 1). Thus of the 19 gastric tumour tissues, expression of $\alpha$-catenin was completely lost in seven (37\%) and decreased in six (32\%) compared with normal tissue (fig 1). In total, 13 (69\%) tumour specimens exhibited low or absent $\alpha$-catenin expression whereas in the tumour free locations reduced $\alpha$-catenin expression or absence of $\alpha$-catenin expression was observed in only four cases. Statistical analysis by $\chi^{2}$ test revealed that mRNA expression of $\alpha$-catenin in the tumour location was significantly reduced compared with non-tumorous locations $(\mathrm{p}<0.05)$ (fig 2$)$. Of the 19 gastric cancer specimens, nine were of the intestinal-type and nine of the diffusetype. Seven of nine diffuse-type gastric cancers exhibited low $\alpha$-catenin expression in addition to six of nine gastric cancers of the intestinaltype; thus there was no difference between

Table 1 a-Catenin expression in gastric cancer patients

\begin{tabular}{llllllll}
\hline Pts & Age & Sex & Hp & Tumour & Tumour free & Histology & $\begin{array}{l}\text { Lauren } \\
\text { classification }\end{array}$ \\
\hline 1 & 65 & F & + & + & \pm & Adeno & Diffuse \\
2 & 69 & M & + & \pm & - & Adeno & Diffuse \\
3 & 71 & M & + & + & + & Adeno & Intestinal \\
4 & 55 & M & + & + & - & Signet ring & Diffuse \\
5 & 60 & F & + & + & - & Signet ring & Diffuse \\
6 & 62 & F & - & + & - & Adeno & Intestinal \\
7 & 73 & M & - & + & + & Small cell & \\
8 & 69 & F & + & + & + & Adeno & Diffuse \\
9 & 37 & M & - & + & + & Adeno & Intestinal \\
10 & 63 & M & - & + & + & Adeno & Intestinal \\
11 & 69 & M & + & + & \pm & Adeno & Diffuse \\
12 & 63 & M & + & + & \pm & Adeno & Intestinal \\
13 & 69 & M & - & + & \pm & Adeno & Intestinal \\
14 & 66 & F & - & + & \pm & Signet ring & Diffuse \\
15 & 35 & M & + & - & - & Signet ring & Diffuse \\
16 & 57 & F & + & - & + & Signet ring & Diffuse \\
17 & 64 & F & + & + & + & Adeno & Intestinal \\
18 & 54 & F & + & + & - & Adeno & Intestinal \\
19 & 63 & F & - & - & - & Signet ring & Diffuse \\
\hline
\end{tabular}

+ , positive; \pm , faint band, - , negative.

$\mathrm{Hp}$, Helicobacter pylori.

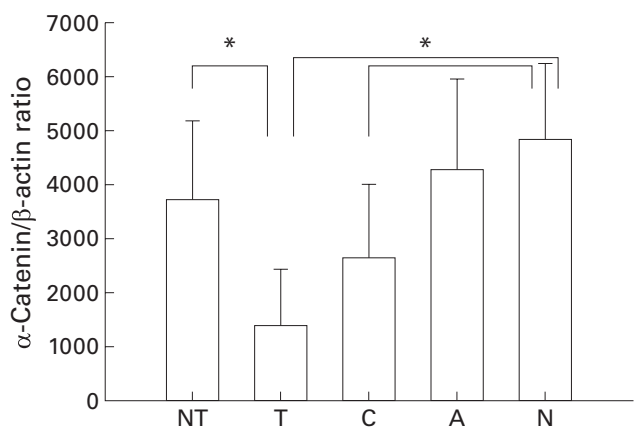

Figure 2 Semiquantitative RT-PCR analysis of a-catenin expression. NT, non-tumour; T, tumour; $C$, corpus from first degree relatives; $A$, antrum from first degree relatives; $N$, healthy subjects. ${ }^{\star} p<0.05$.

$\alpha$-catenin expression in the different histological types (table 1). Immunohistochemical analysis revealed membranous staining for $\alpha$-catenin in non-malignant gastric epithelium of healthy controls (fig 3A). Immunoreactivity was abundant along the cell membranes (arrowheads) and cytoplasmic immunoreactivity was also observed in the non-malignant gastric mucosa (fig 3A). In gastric cancers, $\alpha$-catenin expression was also membranous and cytoplasmic (fig 3B). However, some areas of the gastric cancers exhibited decreased $\alpha$-catenin immunoreactivity (fig 3C). Expression of $\alpha$-catenin in the tumour free gastric mucosa of gastric cancer patients was however not different from the membranous staining in the gastric mucosa of healthy individuals (not shown).

EXPRESSION OF $\alpha$-CATENIN IN THE GASTRIC

MUCOSA OF FIRST DEGREE RELATIVES

A total of 18 first degree relatives were examined for $\alpha$-catenin mRNA expression using gastric tissues obtained from the corpus and antrum (table 2). In the biopsies obtained from the corpus, reduced levels of $\alpha$-catenin expression were seen in six cases and no $\alpha$-catenin expression in five (fig 1 ). In the antrum, decreased levels were observed in one case and loss of $\alpha$-catenin expression was observed in three biopsies. Thus in the corpus biopsies $\alpha$-catenin expression was more often decreased or lost than in the antrum biopsies in first degree relatives $(\mathrm{p}<0.05)$. In comparison with the gastric tissues from eight normal subjects, downregulation of $\alpha$-catenin expression was found more frequently in tumour tissues $(p<0.05)$ and in the corpus of relatives $(\mathrm{p}<0.05)$, but there was no significant variation between biopsies from normal subjects compared with non-tumorous tissues of cancer patients and antrum biopsies of first degree relatives (fig 2). Immunohistochemical analysis confirmed the membranous and cytoplasmic expression of $\alpha$-catenin in the gastric mucosa of these high risk individuals. No difference in staining pattern was observed compared with healthy controls (fig 3A).

CORRELATION OF $\alpha$-CATENIN EXPRESSION WITH $H$ PYLORI INFECTION

Of 35 tissue specimen obtained from the corpus and antrum of first degree relatives, the 


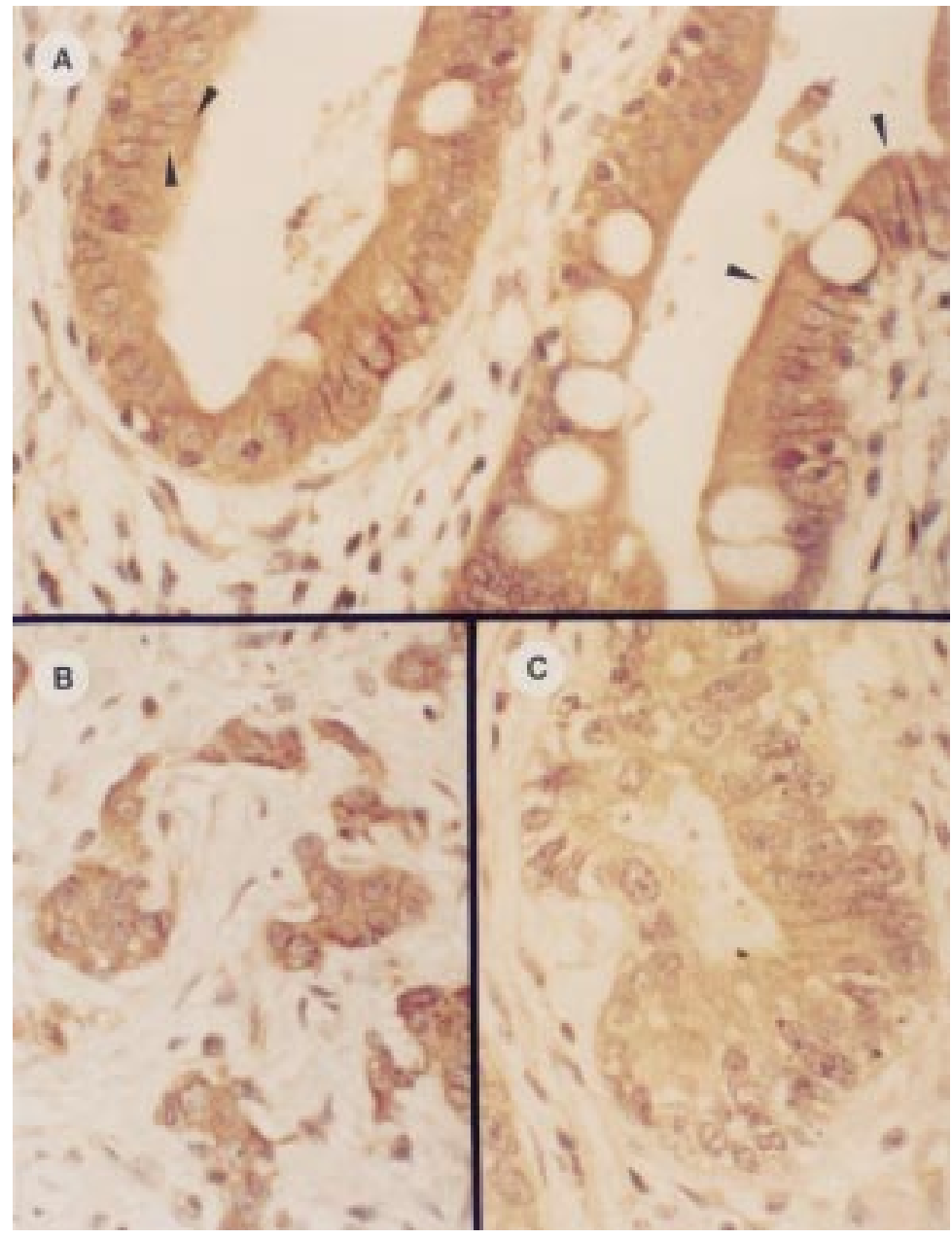

Figure 3 Immunohistochemical analysis of a-catenin expression. In the normal gastric epithelium, a-catenin immunoreactivity was located at the cell membrane ( $A$, arrowheads) and in the cytoplasm. Gastric cancer cells exhibited various levels of cytoplasmic and/or membranous immunoreactivity in diffuse-type (B) or intestinal-type (C) gastric

carcinoma. In some cases a-catenin immunoreactivity was decreased in the gastric cancer cells $(C)$.

gastritis grade was classified histologically as severe in six cases, as moderate in 16 cases, and as minimal in nine cases. In four cases no gas-

Table $2 a$-Catenin expression in first degree relatives

\begin{tabular}{|c|c|c|c|c|c|c|c|c|c|c|}
\hline \multirow[b]{3}{*}{ No } & \multirow[b]{3}{*}{ Age } & \multirow[b]{3}{*}{ Sex } & \multirow[b]{3}{*}{$H p$} & \multicolumn{3}{|c|}{ Corpus } & \multicolumn{3}{|c|}{ Antrum } & \multirow[b]{3}{*}{$I M$} \\
\hline & & & & \multicolumn{2}{|c|}{ Gastritis } & \multirow[b]{2}{*}{ a-Catenin } & \multicolumn{2}{|c|}{ Gastritis } & \multirow[b]{2}{*}{$a$-Catenin } & \\
\hline & & & & $G$ & $A$ & & $G$ & $A$ & & \\
\hline 1 & 44 & $\mathrm{~F}$ & + & 2 & 2 & \pm & 2 & 2 & \pm & - \\
\hline 2 & 42 & $\mathrm{~F}$ & - & 1 & 0 & - & 1 & 0 & + & - \\
\hline 3 & 42 & $\mathrm{~F}$ & - & 3 & 2 & - & 2 & 0 & + & - \\
\hline 4 & 29 & $M$ & + & 1 & 1 & - & 2 & 2 & - & - \\
\hline 5 & 30 & $\mathrm{~F}$ & - & 0 & 0 & + & 0 & 0 & + & - \\
\hline 6 & 38 & $M$ & + & 2 & 2 & \pm & 2 & 1 & + & - \\
\hline 7 & 65 & $M$ & + & 2 & 2 & \pm & 2 & 2 & + & - \\
\hline 8 & 55 & $\mathrm{~F}$ & + & 2 & 2 & + & 3 & 2 & - & + \\
\hline 9 & 60 & $\mathrm{~F}$ & + & 2 & 2 & + & 2 & 2 & + & - \\
\hline 10 & 30 & $\mathrm{~F}$ & - & 2 & 2 & + & 1 & 0 & + & + \\
\hline 11 & 64 & $\mathrm{~F}$ & + & 1 & 1 & + & 2 & 2 & + & - \\
\hline 12 & 71 & $\mathrm{~F}$ & + & 1 & 1 & - & 2 & 2 & + & - \\
\hline 13 & 23 & $\mathrm{~F}$ & + & 2 & 2 & + & 3 & 2 & - & + \\
\hline 14 & 27 & $\mathrm{~F}$ & - & 1 & 0 & \pm & 1 & 0 & + & - \\
\hline 15 & 50 & $\mathrm{~F}$ & + & 3 & 2 & \pm & 3 & 3 & + & + \\
\hline 16 & 64 & $\mathrm{~F}$ & - & 0 & 0 & + & 0 & 0 & + & - \\
\hline 17 & 61 & $\mathrm{~F}$ & + & 2 & 1 & - & 3 & 2 & + & - \\
\hline 18 & 45 & $M$ & - & 1 & 1 & \pm & nd & nd & + & - \\
\hline
\end{tabular}

+ , positive; \pm , faint band; - , negative.

G, grade; A, activity: 0, no gastritis/activity; 1, minimal gastritis/activity; 2, moderate gastritis/activity; 3 , severe gastritis/high activity

IM, intestinal metaplasia; Hp, Helicobacter pylori; nd, not determined. tritis was observed. Furthermore, the activity of gastritis was classified as low or moderate in 24 cases, whereas 10 cases exhibited no activity (table 2). No significant difference was found between the grade or activity of gastritis and the level of $\alpha$-catenin expression. Interestingly, of the four biopsies with intestinal metaplasia, three cases exhibited low $\alpha$-catenin expression (table 2). $H$ pylori infection and mRNA expression of $\alpha$-catenin was studied in 64 tissues from relatives and in the tumour free gastric mucosa of gastric cancer patients (table 3). Seventeen of 19 tissue specimens with $H$ pylori infection exhibited reduced or no $\alpha$-catenin expression, whereas in 22 tissue specimens with no $H$ pylori infection only six exhibited low or no $\alpha$-catenin expression. Statistical analysis by Fisher's exact test confirmed that reduced and/or no $\alpha$-catenin expression was associated with $H$ pylori infection $(\mathrm{p}<0.05)$ (table 3$)$.

\section{Discussion}

Intercellular interactions are critical for the establishment and maintenance of normal cell morphology, differentiation, and growth control. Furthermore, disturbance or loss of normal cell-cell interactions as a result of defects in the function of adherens junctions may have a critical role in the malignant transformation of cells. Normal epithelial cells bind tightly to each other whereas cancer cells exhibit impaired adhesion. ${ }^{40}$ E-cadherin is a $120 \mathrm{kDa}$ transmembrane glycoprotein that plays an important role in the organisation and maintenance of tissue structure by homotypic adhesion. ${ }^{12}$ E-cadherin is associated via its cytoplasmic domain with a group of catenins, including $\alpha$-catenin, $\beta$-catenin, and $\gamma$-catenin/ plakoglobin which act to couple the cadherins to the microfilament of the cytoskeleton. ${ }^{8}$ $\beta$-Catenin and $\gamma$-catenin/plakoglobin, both members of the armadillo protein family, link E-cadherin via $\alpha$-catenin to the actin cytoskeleton. ${ }^{128}$ Recently, several studies have demonstrated that expression of E-cadherin and catenins is frequently downregulated in a number of human cancers. ${ }^{14}{ }^{16}{ }^{23}$ Furthermore, several groups have reported frequent mutations of the E-cadherin gene in various epithelial cancers. ${ }^{13}$ Thus it has been demonstrated by several groups that downregulation of E-cadherin expression and mutations of the E-cadherin gene occur in a subgroup of breast and gastric cancers. ${ }^{13} 162324$ Interestingly, germline mutations of E-cadherin have also been reported in familial gastric cancer. ${ }^{25}$ In addition, an extensive study of E-cadherin and catenin expression in a large series of gastric cancers by immunohistochemical analysis has revealed a high frequency of abnormal expression of the E-cadherin-catenin complex in gastric cancers. ${ }^{14}$ In our study we also found loss of membranous $\alpha$-catenin immunoreactivity in a subgroup of gastric cancer patients. However, our analysis of $\alpha$-catenin mRNA levels revealed a further interesting difference between the normal gastric epithelium and gastric cancer cells. In our analysis $\alpha$-catenin expression was present in the gastric mucosa of all healthy individuals whereas in the tumour tissues 
Table $3 a$-Catenin expression in tissues with $(\mathrm{HP}+)$ or without (HP-) H pylori infection

\begin{tabular}{|c|c|c|c|c|}
\hline & \multirow[b]{2}{*}{$n$} & \multicolumn{2}{|c|}{$a$-Catenin expression } & \multirow[b]{2}{*}{$p$ Value } \\
\hline & & + & $-o r \pm$ & \\
\hline $\mathrm{HP}+$ & 36 & 19 & 17 & $<0.05$ \\
\hline $\mathrm{HP}-$ & 28 & 22 & 6 & \\
\hline
\end{tabular}

+ , positive; \pm , faint band; - , negative.

expression of $\alpha$-catenin was lost or at least decreased in $69 \%$ of cases. The high frequency of decreased $\alpha$-catenin mRNA levels in gastric cancers compared with normal gastric tissues obtained from healthy subjects highlights an important role of $\alpha$-catenin in cell adhesion and maintenance of normal epithelial morphology in the healthy stomach, with the observed alteration in gastric cancer indicating decreased $\alpha$-catenin expression in the development of gastric cancers. Our data are in line with previous reports which revealed alteration of $\alpha$-catenin expression in $50-70 \%$ of gastric cancers. ${ }^{14}{ }^{15}$ However, these studies were based on immunohistochemical analyses and alteration of $\alpha$-catenin expression was defined as abnormal non-membranous immunoreactivity in gastric cancer cells. Using a different approach, we demonstrated decreased levels of $\alpha$-catenin mRNA in gastric cancer tissue specimens. In addition, our study revealed that $\alpha$-catenin expression was abnormal in seven of nine diffuse-type cancers and in six of nine intestinal-type cancers. Thus although the number of cancer cases was small, we could not find a correlation between $\alpha$-catenin expression and histological type of cancer according to the Lauren classification. This observation is compatible with data reported by Jawhari and colleagues. ${ }^{14}$ However, these authors revealed an association between abnormal expression of E-cadherin and $\gamma$-catenin and the diffuse-type gastric cancer. ${ }^{14}$

The pathogenesis of gastric cancer remains largely unknown. Although a number of genetic and molecular alterations have been described in gastric carcinoma, the exact sequence and number of genetic or molecular alterations are not yet known. ${ }^{26}$ Apart from activation of oncogenes such as c-met and $K$-sam and inactivation of $p 53$ and $A P C$, alteration of adhesion molecules seems to be critical for the development of gastric cancers. ${ }^{24-28} \mathrm{Sev}$ eral models on how histomorphological changes of the gastric mucosa lead to the transformation of the gastric mucosa and the development of gastric cancer have been postulated. The best known was proposed by Correa et al who described the development of gastric tumours from gastritis to intestinal metaplasia, dysplasia, and eventually gastric cancer. ${ }^{29}$ Further studies have demonstrated that some histological changes, such as the presence of intestinal metaplasia or a corpus dominant gastritis in conjunction with intestinal metaplasia, define a group of individuals with an increased risk of developing gastric cancer. $^{30}{ }^{31}$ Epidemiological analyses have shown that the incidence of gastric cancer in first degree relatives of patients with gastric cancer is increased threefold compared with the normal population. ${ }^{32}{ }^{33}$ In addition, severe corpus mucosal atrophy has been reported in the stomach of these individuals and is associated with an increased risk of developing gastric cancer in this subgroup. ${ }^{34}$ Recently, Meining et al have shown that cell proliferation in the gastric mucosa of first degree relatives of patients with gastric cancer is increased compared with normal controls and that this increased proliferation is independent of $H$ pylori infection. ${ }^{35}$ Thus these studies have defined a subgroup of individuals with an increased risk of developing gastric cancer. Our analysis aimed at evaluating the role of $\alpha$-catenin expression in the development of gastric cancer and its expression in the subgroup of these individuals with an increased risk of gastric cancer. Although immunohistochemical analysis did not reveal alteration of $\alpha$-catenin protein expression in cancer relatives compared with healthy controls, we found that in the gastric mucosa of these individuals $\alpha$-catenin mRNA levels in the corpus were downregulated compared with healthy controls. Moreover, expression of $\alpha$-catenin in the corpus biopsies of these individuals was significantly lower than that in matched antrum biopsies. Although it seems as if $\alpha$-catenin mRNA levels in the corpus biopsies from cancer relatives were lower compared with the non-tumour tissues of gastric cancer patients in our densitometric analysis, we believe that this reduction was caused by the heterogeneous sampling locations of non-tumour tissues in cancer patients and thus expression of $\alpha$-catenin cannot be compared between these two groups. None the less, to our knowledge this is the first study reporting significant molecular changes of the gastric mucosa in this subgroup of individuals with an increased risk of gastric cancer. These observations support histomorphological findings which have determined an increased risk of cancer in siblings of gastric cancer patients who present with severe atrophy of the corpus mucosa. Furthermore, the presence of a corpus dominant gastritis together with intestinal metaplasia also contributes to an increased risk of gastric cancer. $^{3031}$ Our data extend these findings to the molecular level. $\alpha$-Catenin mRNA levels were more often decreased in the corpus than in the antrum of individuals with an increased risk of developing gastric cancer and the mean level of expression in the corpus biopsies of these individuals was comparable with that in gastric cancer. In summary, our observation of decreased $\alpha$-catenin expression in the corpus mucosa of first degree relatives raises the hypothesis that changes in the expression of $\alpha$-catenin in the corpus mucosa in the presence of severe gastritis may represent early changes in the process of malignant transformation of the gastric mucosa.

$H$ pylori was classified as a group I carcinogen by the International Agency for Research on Cancer in 1994 and several groups have reported that $H$ pylori infection leads to enhanced cell proliferation and diminished apoptosis of the gastric mucosa, both 
features common in the process of malignant transformation. ${ }^{26}{ }^{36} 37$ Terres et al reported that $H$ pylori infected individuals exhibit downregulation of E-cadherin expression in the antrum but no alteration of alpha 6-integrin or extracellular matrix protein expression (for example, collagen IV, fibronectin, or laminin) was reported. ${ }^{36}$ We analysed the association of $H$ pylori infection and alteration of $\alpha$-catenin expression in a series of non-malignant gastric biopsies obtained from gastric cancer patients and high risk individuals and found an association between $H$ pylori infection and decreased $\alpha$-catenin expression. Thus together with previous reports revealing increased cell proliferation, diminished apoptosis, and downregulation of E-cadherin expression in the gastric mucosa of $H$ pylori infected individuals, our findings of downregulation of $\alpha$-catenin mRNA levels in this subgroup of individuals indicates the presence of multiple cellular and molecular alterations in the gastric mucosa of these individuals which may precede the development of gastric cancer.

In summary, we have shown that loss of $\alpha$-catenin is common in gastric cancer, occurs in a proportion of first degree relatives, and is closely associated with $H$ pylori infection. The presence of altered $\alpha$-catenin expression in first degree relatives of patients with gastric cancer raises the hypothesis that molecular changes are present in the histologically tumour free gastric mucosa and may precede the development of gastric cancer. Further studies are necessary to assess the role of $\alpha$-catenin mRNA levels for the identification of individuals with an increased risk of developing gastric cancer and their clinical management.

The study was supported by grants from the Land SachsenAnhalt $(2775 \mathrm{~A} / 0087 \mathrm{H})$ and the Deutsche Forschungsgemeinschaft $($ Eb 187/1-1,1-2) awarded to M P A Ebert. Patients were schaft (Eb $187 / 1-1,1-2)$ awarded
enrolled for the PRISMA trial.

1 Uemura T. The cadherin superfamily at the synapse: more members, more missions. Cell 1998;93:1095-8.

2 Takeichi M. Cadherin cell adhesion receptors as a morphogenetic regulator. Science 1991;251:1451-5.

3 Nose A, Takeichi M. A novel cadherin cell adhesion Nose A, Takeichi M. A novel cadherin cell adhesion
molecule: its expression patterns associated with implantamolecule: its expression patterns associated with implanta-
tion and organogenesis of mouse embryos. 7 Cell Biol 1986; tion and organ
103:2649-58.

4 Jawhari A, Farthing M, Pignatelli M. The importance of the E-cadherin-catenin complex in the maintenance of intestinal epithelial homeostasis: more than intercellular glue? Gut 1997;41:581-4

5 Ozawa M, Ringwald M, Kemler R. Uvomorulin-catenin complex formation is regulated by a specific domain in the cytoplasmic region of the cell adhesion molecule. Proc Nat Acad Sci USA 1990;87:4246-50.

6 Kintner C. Regulation of embryonic cell adhesion by the cadherin cytoplasmic domain. Cell 1992;69:225-36.

7 Vestweber D, Kemler R. Some structural and functional aspects of the cell adhesion molecule uvomorulin. Cell Differ 1984;15:269-73.

8 Ozawa M, Baribault H, Kemler R. The cytoplasmic domain of the cell adhesion molecule uvomorulin associates with of the cell adhesion molecule uvomorulin associates with three independent proteins structurall
species. $E M B O \mathcal{F} 1989 ; 8: 1711-17$.

9 Ozawa M, Kemler R. Molecular organization of the uvomorulin-catenin complex. F Cell Biol 1992;116:989-96.

10 Shimoyama Y, Nagafuchi A, Fujita S, et al. Cadherin dysfunction in a human cancer cell line: possible involve- ment of loss of alpha-catenin expression in reduced cell-cell adhesiveness. Cancer Res 1992;52:5770-4.

11 Pignatelli M, Vessey CJ. Adhesion molecules: novel molecular tools in tumor pathology. Hum Pathol 1994;25:849-56.

12 Matsuura K, Kawanishi J, Fujii S, et al. Altered expression of E-cadherin in gastric cancer tissues and carcinomatous fluid. Br F Cancer 1992;66:1122-30.

13 Becker KF, Atkinson MJ, Reich U, et al. E-cadherin gene mutations provide clues to diffuse type gastric carcinomas. Cancer Res 1994;54:3845-52.

14 Jawhari A, Jordan S, Poole S, et al. Abnormal immunoreactivity of the E-cadherin-catenin complex in gastric carcinoma: relationship with patient survival. Gastroenterology 1997;112:46-54

15 Matsui S, Shiozaki H, Inoue M, et al. Immunohistochemical evaluation of alpha-catenin expression in human gastric cancer. Virchows Arch 1994;424:375-81.

16 Rimm DL, Sinard JH, Morrow JS. Reduced alpha-catenin and E-cadherin expression in breast cancer. Lab Invest 1995;72:506-12.

17 Dixon MF, Genta RM, Yardley JH, et al. Classification and grading of gastritis. The updated Sydney System. International Workshop on the Histopathology of Gastritis, Houston 1994. Am f Surg Pathol 1996;20:1161-81.

18 Ebert M, Yokoyama M, Kobrin MS, et al. Induction and expression of amphiregulin in human pancreatic cancer. Cancer Res 1994;54:3959-62.

19 Furukawa Y, Nakatsuru S, Nagafuchi A, et al. Structure, expression and chromosome assignment of the human catenin (cadherin-associated protein) alpha 1 gene (CTNNA 1). Cytogenet Cell Genet 1994;65:74-8.

20 Kim SW, Harney JW, Larsen PR. Studies of the hormonal regulation of type 25 '-iodo-thyronine deiodinase messenger ribonucleic acid in pituitary tumor cells using semiquantitative reverse transcription-polymerase chain reaction. Endocrinology 1998;139:4895-905.

21 Rohwedel J, Guan K, Zuschratter W, et al. Loss of betal integrin function results in a retardation of myogenic, but an acceleration of neuronal, differentiation of embryonic stem cells in vitro. Dev Biol 1998;201:167-84.

22 Siegel S. Nonparametric statistics for behavioral sciences. New York: McGraw-Hill, 1956.

23 Pierceall WE, Woodard AS, Morrow JS, et al. Frequent alterations in E-cadherin and alpha-and beta-catenin expression in human breast cancer cell lines. Oncogene 1995;11:1319-26.

24 Berx G, Becker KF, Höfler H, et al. Mutations of the human E-cadherin (CDH1) gene. Hum Mutat 1998;12:226-37.

25 Guilford P, Hopkins J, Harraway J, et al. E-cadherin germline mutations in familial gastric cancer. Nature 1998; 392:402-5.

26 Delchier JC, Ebert M, Malfertheiner P. Helicobacter pylori in gastric lymphoma and carcinoma. Curr Opin Gastroenterol 1998;14:41-5.

27 Fuchs CS, Mayer RJ. Gastric carcinoma. N Engl f Med 1995;333:32-41.

28 Tahara E, Semba S, Tahara H. Molecular biological observations in gastric cancer. Semin Oncol 1996;23:30715.

29 Correa P. Human gastric carcinogenesis: a multistep and multifactorial process-first American Cancer Society Award Lecture on cancer epidemiology and prevention. Cancer Res 1992;52:6735-40.

30 Meining A, Stolte M, Hatz R, et al. Differing degree and distribution of gastritis in Helicobacter pylori-associated diseases. Virchows Arch 1997;431:11-15.

31 Miehlke S, Hackelsberger A, Meining A, et al. Severe expression of corpus gastritis is characteristic in gastric cancer patients infected with Helicobacter pylori. Int $\mathcal{F}$ Cancer 1997;73:837-9.

32 Zanghieri G, Di Gregorio C, Sacchetti C, et al. Familial occurrence of gastric cancer in the 2-year experience of a population-based registry. Cancer 1990;66:2047-51.

33 La Vecchia C, Negri E, Franceschi S, et al. Family history and the risk of stomach and colorectal cancer. Cancer 1992;70:50-5.

34 Kekki M, Ihamäki T, Varis K, et al. Chronic gastritis profiles in sibs of probands calculated to carry a highly increased risk of gastric carcinoma. Scand f Gastroenterol 1991;26:2932

35 Meining A, Hackelsberger A, Daenecke C, et al. Increased cell proliferation of the gastric mucosa in first-degree relatives of gastric carcinoma patients. Cancer 1998;83:876-81.

36 Terres AM, Pajares JM, O'Toole D, et al. H. pylori infection is associated with downregulation of E-cadherin, a molecule involved in epithelial cell adhesion and proliferation control. F Clin Pathol 1998;51:410-2.

37 Fan XG, Kelleher D, Fan XJ, et al. Helicobacter pylori increases proliferation of gastric epithelial cells. Gut 1996;38:19-22. 